\title{
Chromosomal Imbalances in Patients with Congenital Cardiac Defects: A Meta-analysis Reveals Novel Potential Critical Regions Involved in Heart Development
}

\author{
Thor Thorsson, MD, ${ }^{*}$ William W. Russell, ${ }^{*}$ Nour El-Kashlan, ${ }^{*}$ Rachel Soemedi, PhD, ${ }^{\dagger}$ \\ Jonathan Levine, ${ }^{*}$ Sarah B. Geisler, MS, ${ }^{*}$ Todd Ackley, PhD, ${ }^{\ddagger}$ Aoy Tomita-Mitchell, PhD, $\$$ \\ Jill A. Rosenfeld, MS, CGC, " Ana Töpf, PhD, ${ }^{* *}$ Marwan Tayeh, PhD, ${ }^{\ddagger}$ Judith Goodship, PhD, ${ }^{* *}$ \\ Jeffrey W. Innis, MD, PhD, ${ }^{\neq \dagger \dagger}$ Bernard Keavney, MD, ${ }^{\ddagger \ddagger}$ and Mark W. Russell, MD* \\ Department of Pediatrics and Communicable Diseases, Divisions of *Pediatric Cardiology and ₹Pediatric Genetics, \\ University of Michigan, Ann Arbor, Mich, USA; ${ }^{\dagger}$ Center for Computational Molecular Biology, Brown University, \\ Providence, RI, USA; 'Department of Surgery, Medical College of Wisconsin, Milwaukee, Wis, USA; "Signature Genomic \\ Laboratories, PerkinEImer, Inc., Spokane, Wash, USA; **Institute of Genetic Medicine, Newcastle University, Newcastle \\ upon Tyne, United Kingdom; ${ }^{\dagger}$ Department of Human Genetics, University of Michigan, Ann Arbor, Mich, USA; 非Institute \\ of Cardiovascular Sciences, Central Manchester University, Manchester, United Kingdom
}

\section{A B S T R A C T}

Objective. Congenital cardiac defects represent the most common group of birth defects, affecting an estimated six per 1000 births. Genetic characterization of patients and families with cardiac defects has identified a number of genes required for heart development. Yet, despite the rapid pace of these advances, mutations affecting known genes still account for only a small fraction of congenital heart defects suggesting that many more genes and developmental mechanisms remain to be identified.

Design. In this study, we reviewed 1694 described cases of patients with cardiac defects who were determined to have a significant chromosomal imbalance (a deletion or duplication). The cases were collected from publicly available databases (DECIPHER, ISCA, and CHDWiki) and from recent publications. An additional 68 nonredundant cases were included from the University of Michigan. Cases with multiple chromosomal or whole chromosome defects (trisomy 13, 18, 21) were excluded, and cases with overlapping deletions and/or insertions were grouped to identify regions potentially involved in heart development.

Results. Seventy-nine chromosomal regions were identified in which 5 or more patients had overlapping imbalances. Regions of overlap were used to determine minimal critical domains most likely to contain genes or regulatory elements involved in heart development. This approach was used to refine the critical regions responsible for cardiac defects associated with chromosomal imbalances involving 1q24.2, 2q31.1, 15q26.3, and 22q11.2.

Conclusions. The pattern of chromosomal imbalances in patients with congenital cardiac defects suggests that many loci may be involved in normal heart development, some with very strong and direct effects and others with less direct effects. Chromosomal duplication/deletion mapping will provide an important roadmap for genome-wide sequencing and genetic mapping strategies to identify novel genes critical for heart development.

Key Words. Heart Development; Chromosomal Imbalance; Congenital Heart Defects

Disclosures: JAR is an employee of Signature Genomic Laboratories, a subsidiary of PerkinElmer, Inc. Funding: Braylon's Gift of Hope Fund (MWR) Aaron Stern Professorship (MWR)

Morton S and Henrietta K. Sellner Professorship (JWI)

(C) 2014 Wiley Periodicals, Inc.

\section{Introduction}

he high morbidity and mortality associated 1 with severe congenital cardiac defects has stimulated the search for new strategies to decrease their frequency, reduce their severity and improve their treatment. While advances in surgical and medical care have substantially improved

Congenit Heart Dis. 2015;10:193-208 
patient outcomes, recent studies suggest morbidity and mortality remains high for some of the most severe defects and that further improvements in outcomes may depend on the development of new therapeutic approaches. ${ }^{1,2}$ However, our ability to reduce the incidence or severity of heart defects is limited by an incomplete understanding of their causes. ${ }^{3}$ Previous studies have identified genes responsible for some types of congenital heart defects (CHDs). ${ }^{4,5}$ To date, the identified genes appear to account for only a small percentage of the observed cases. This suggests that the pathophysiology of congenital heart disease is quite complex, potentially involving a large number of genes and genetic defects with variable levels of expressivity. Similar to other disorders demonstrating a complex pattern of inheritance, CHDs may often depend on the concurrent inheritance of multiple predisposing genetic factors that interact with epigenetic or environmental influences to result in impaired structural development. ${ }^{6}$ The current challenge therefore is to identify such predisposing genetic factors that contribute to heart defects to aid development of new therapeutic strategies.

To meet this challenge, a number of approaches have been used to identify genes responsible for cardiac defects. In addition to the characterization of rare families with clear patterns of inheritance, targeted sequencing of genes determined to be potentially involved in heart development, either based on functional analysis in animal models or mapping chromosomal deletions/duplications in patients, has been successful in identifying causative mutations in patients with CHD. ${ }^{3}$ In patients without significant chromosomal imbalances or clear familial inheritance, whole exome sequencing strategies have been utilized to identify disease-causing mutations in known or novel heart development genes. ${ }^{7}$ Unfortunately, these nondirected sequencing strategies identify hundreds of novel genetic variants of unknown significance for each patient. Prioritizing sequence variants for further evaluation depends on (1) the identification of potentially pathogenic mutations using bioinformatics; (2) the identification and characterization of genes expressed in the tissues that contribute to cardiac development; and (3) the characterization of genetic and genomic abnormalities in other patients with congenital cardiac defects.

In this study, we sought to develop a roadmap for the prioritization of novel genetic variants in patients with heart defects by identifying genomic regions associated with congenital heart disease based on the mapping of chromosomal imbalances. Chromosomal imbalances occur approximately in $8-13 \%$ of patients with $\mathrm{CHDs}^{8}$ and may represent important opportunities to localize and identify genes potentially involved in human cardiac development and the genesis of CHDs. In our review of publicly available databases and publications, we identified 1694 patients with a chromosomal imbalance (duplication or deletion) and congenital cardiac malformations. In addition, we identified 68 patients from our own institution. Patients with overlapping genomic abnormalities were grouped to identify minimal critical regions encompassing potential candidate genes involved in human cardiac development. We identified 79 chromosomal regions in which duplications or deletions have resulted in CHDs in five or more patients. Several of the regions identified have been noted previously to be involved in cardiac development including recurring deletions on chromosomes 7 and 22 (Williams and DiGeorge syndromes), and chromosomes 5 and 8 (involving the cardiac transcription factors NKX2-5 and GATA4). In addition, multiple sets of overlapping deletions and/or duplications were identified that may represent the locations of novel genes involved in cardiac development.

\section{Methods}

\section{Database Search}

The following three sources were used to identify patients for analysis: (1) the DECIPHER database (an international database containing genomic and phenotypic information on patients from over 150 centers in 29 countries) $)^{9}$; (2) the International Standards for Cytogenomic Arrays (ISCA) consortium; and (3) the Benchv3.3 beta database. For each database, a series of search terms were used to identify cases involving CHDs. For the DECIPHER database, the search term "heart" was used to identify patients with CHDs. For the ISCA database, the following search terms were used: atrial septal defect (ASD), AV canal defect, coarctation of the aorta (CoA), hypoplastic left heart, tetralogy of Fallot (TOF), ventricular septal defect (VSD), and heart. The Benchv3.3 database included a linked site for identified cases with CHDs (http:// homes.esat.kuleuven.be/ bioiuser/chdwiki/index .php/CHD:Reports). ${ }^{10}$

\section{Expansion of the Database Using Published Data}

In addition, data were pooled from four recent publications examining the contribution of copy 
number variation to the pathogenesis of CHDs. ${ }^{11-14}$ The formats used for copy number variant $(\mathrm{CNV})$ identification and verification are described in each publication. Only those cases in which a single or primary CNV could be identified were included in the database for this study. Cases with more than one $\mathrm{CNV}$ were included if the "secondary" CNVs were known to be common in the general population and were less than $100 \mathrm{~kb}$ in size. Patients with identical recorded phenotypes and identical genomic imbalances represented in multiple databases and/or publications were deemed to be the same patient and were recorded only once.

\section{Mapping of CNVs}

For each case, the deleted or duplicated intervals had been previously mapped to the human genome reference sequence using the NCBI36/ hg18 or GRCh37/hg19 genome builds. All sequences were converted to the numbering of the GRCh37/hg19 genome build using the LiftOver program (http://genome.ucsc.edu/cgi-bin/ hgLiftOver). For those sequences not successfully converted by the LiftOver program, approximate boundaries were determined using nearby genes and markers in the NCBI36/hg18 genome build and locating the corresponding markers/genes on the GRCh37/hg19 genome map. As those boundaries are less definite, they are represented in red in the composite database.

\section{Grouping of Cases with Overlapping CNVs}

There are many approaches to group the observed cases. The full database can be retrieved and resorted based on specific interests or scientific questions. We have presented one approach, but there are many alternatives. To identify regions of overlap, the cases were sorted by chromosome and then sequentially by proximal and distal boundary location (using the GRCh37/hg19 genome build). Eighty-one regions with at least five cases of overlapping duplications and/or deletions were identified by visual inspection. Proximal and distal "secondary" boundaries were determined based on the presence of at least one case with a breakpoint internal to the proposed boundary. This was done to ensure that an important candidate gene would not be excluded based on a single breakpoint in an individual case. The candidate region was identified using the UCSC Genome Browser on Human Feb. 2009 (GRCh37/ hg19) Assembly (http://genome.ucsc.edu/cgi-bin/ hgGateway?hgsid=353279827). A list of genes in the region was recorded and examined for candidate genes known or suspected to have a role in human heart development. If a definite candidate was present, it was used to organize the overlapping cases in that all cases involving that locus were grouped prior to grouping the cases near but not involving the known cardiac gene. After regrouping based on candidate genes, a total of 79 candidate regions affected in five or more patients were identified.

\section{Estimate of Percentage of Chromosomal Imbalances Associated with Congenital Cardiac Defects}

For each of the 79 regions affected (included in a deletion or duplication) in five or more CHD patients, a candidate gene within the minimal region was identified and used to determine the copy number of that candidate region (recognizing that the selected gene may or may not be the one responsible for the observed cardiac defects). To determine if the incidence of cardiac defects associated with the gain or loss of that locus was in excess of what would be expected from a normal control population, we compared the rate of gain or loss of each locus in a population of patients referred to Signature Genomics for microarray testing with a diagnosis of a known cardiac defects $(\mathrm{n}=1964)$ and in a control population without known heart disease $(n=8329)$. The analysis was restricted to this dataset as the other datasets were more subject to ascertainment bias making an accurate estimate of the denominator less reliable. The examined cases are a subset of the prenatal and postnatal cases submitted to Signature Genomics for clinical microarray-based comparative genomic hybridization from 2004 to 2013 $(\mathrm{n}=58980)$ and were tested using a variety of platforms, including targeted and whole-genome bacterial artificial chromosome arrays and wholegenome oligonucleotide-based arrays. This dataset includes all cases described in Cooper et al. ${ }^{13}$ For each candidate region, the percentage of deletions and duplications that were associated with a reported cardiac defect was recorded. To determine if the observed difference between the CHD and control populations were statistically significant, a Wilcoxon signed rank test was used.

\section{University of Michigan Patients}

Retrospective chart review was approved by the Institutional Review Board for Human Subject Research at the University of Michigan. Chromosomal microarray analyses were conducted in the Michigan Medical Genetics Labo- 
ratories at the University of Michigan using two oligonucleotide-based array platforms with whole genome coverage: a custom-designed EMArray Cyto6000 chip (Emory Genetics Laboratory, Decatur, GA, USA), implemented on the Agilent $44 \mathrm{~K}$ platform (Agilent Technologies, Inc., Santa Clara, CA, USA), ${ }^{15}$ and the Illumina CytoSNP12 array. The procedures for array comparative genomic hybridization were performed according to the manufacturer's protocols as described in Quinonez et al. ${ }^{16}$ The HumanCytoSNP-12 BeadChip assay (Illumina, San Diego, CA, USA), which targets the entire genome using $300 \mathrm{~K}$ probes, was performed according to the Infinium HD Ultra protocol provided by the manufacturer (Illumina). Briefly, $200 \mathrm{ng}$ of genomic DNA was used for whole-genome amplification at $37^{\circ} \mathrm{C}$ for 20-24 hours. The amplified DNA was enzymatically fragmented, purified, loaded on the HumanCytoSNP-12 BeadChip, and allowed to hybridize at $48^{\circ} \mathrm{C}$ for $16-24$ hours. Subsequently, the hybridizing DNA on the BeadChip was labeled by enzymatic single base extension and incorporated nucleotides were detected using fluorescently labeled antibodies. Stained BeadChips were scanned using a HiScan (Illumina). Data were generated with GenomeStudio (Illumina) and analyzed with Nexus Copy Number software version 6 (BioDiscovery, Hawthorne, CA, USA).

\section{Results}

The 1694 patients with congenital cardiac defects and chromosomal imbalances were identified in the databases and publications examined in this study, and 68 patients with congenital cardiac defects and chromosomal imbalances were included from our institution. The deletion or duplication was assigned to a specific chromosomal segment based on the available mapping data. The set of genes affected by the chromosomal imbalances were retrieved from the databases and used to develop a minimum overlapping set of genes for each locus. We identified 79 potential genetic loci that were involved in a minimum of five overlapping deletions or duplications (see Table 1 and Supporting Information Table S1).

Distribution of Insertions/Deletions Leading to CHDs

Chromosomal deletions and duplications associated with CHDs were not randomly distributed throughout the genome. There was clustering of
CHD-associated genomic imbalances at particular chromosomal locations, including those involved in known cardiac syndromes and at the telomeres. Telomeric and subtelomeric deletions and duplications associated with congenital cardiac defects involved regions on distal chromosomes $1 \mathrm{p}, 1 \mathrm{q}$, 2q, 3p, 3q, 4p, 5p, 5q, 6p, 8p, 9p, 9q, 10q, 11p, 11q, $12 \mathrm{p}, 14 \mathrm{q}, 15 \mathrm{q}, 16 \mathrm{p}, 16 \mathrm{q}, 17 \mathrm{p}, 17 \mathrm{q}, 18 \mathrm{q}, 19 \mathrm{p}$, and $20 \mathrm{q}$.

\section{Chromosomal Duplication/Deletions Affecting Loci Known to Have a Role in CHD}

As would be expected, there were a number of patients with chromosomal imbalances affecting regions previously determined to have role in heart development. Deletions affecting TBX1 (DiGeorge syndrome) and elastin (Williams syndrome) were identified in 36 and 18 patients, respectively. These deletions may be relatively underrepresented in the databases as they have been well described and there is little incentive to catalogue additional patients with these deletions. Deletions affecting NKX2-5 and GATA4 were identified in 7 and 38 patients, respectively. Five of the patients with $N K X 2-5$ deletions were described as having ASDs with or without other cardiac abnormalities including atrioventricular block in three patients. There was a broad range of defects in patients haplosufficient for GATA4 with the majority being described as atrial or ventricular septal defects and relatively frequently, in 12/38 patients, complete atrioventricular septal defects. This is consistent with a recent finding that copy number variants affecting GATA4 were overrepresented in patients with atrioventricular septal defect (AVSD). ${ }^{12}$

Mutations in transforming growth factor-beta (TGF $\beta$ )-activated kinase (TAB2) have previously been noted in patients with CHDs. ${ }^{17}$ Deletions of $T A B 2$ were noted in 11 patients and a duplication in one patient with a range of cardiac defects including ASDs and VSDs, as well as aortic and pulmonary stenosis. Several other genes previously noted to have deleterious mutations in patients with CHDs were affected by chromosomal imbalances in at least five patients including CRELD1, CHD7, CREBBP, EHMT1, HAND2, and NOTCH1 (Table 1).

\section{Chromosomal Insertions/Deletions Affecting Loci Suspected to Have a Role in CHD}

Other chromosomal imbalances involved loci that contain genes that have been demonstrated in animal models to be involved in heart develop- 
Table 1. Regions with Chromosomal Imbalances Noted in Five or More Patients with Congenital Heart Defects

\begin{tabular}{|c|c|c|c|c|c|c|c|}
\hline Chrom & Location & Gene & Heart Defects & Chrom & Location & Gene & Heart Defects \\
\hline 1 & 934342 & HES4 & ASD; CM; VSD & 9 & 139388896 & NOTCH1 & CoA; VSD; ASD; TOF \\
\hline 1 & 8420172 & RERE & VSD; PS; AVSD & 9 & 140513444 & EHMT1 & VSD; ASD; TOF \\
\hline 1 & 104159999 & AMY2A & VSD; ASD;TOF & 10 & 47658233 & ANTXRL & TOF; PA; VSD \\
\hline 1 & 147228332 & GJA5 & $\begin{array}{l}\text { TOF; AS; ASD; SV; TGA; } \\
\text { COA; VSD }\end{array}$ & 10 & 88516396 & BMPR1A & AVSD; ASD \\
\hline 1 & 170633313 & PRRX1 & VSD & 10 & 117061365 & ATRNL1 & PDA; VSD; TOF \\
\hline 1 & 245912642 & SMYD3 & VSD; PDA; TOF & 10 & 135340867 & CYP2E1 & TOF; VSD \\
\hline 2 & 49210237 & FSHR & TOF; HEART & 11 & 50368318 & LOC646813 & PS; ASD \\
\hline 2 & 108459465 & RGPD4 & ASD; TOF; COA & 11 & 128328656 & ETS1 & VSD; ASD; PDA \\
\hline 2 & 110935964 & NPHP1 & TOF; HLHS; CoA & 11 & 134598320 & NKX6-2 & TOF; CAT; HEART \\
\hline 2 & 175212878 & CIR1 & ASD, VSD, PDA, DORV & 12 & 34175216 & ALG10 & TOF; PS; AVSD \\
\hline 3 & 1134620 & CNTN6 & AVSD; TOF & 12 & 60083118 & SLC16A7 & ASD; PS; CoA; HLHS \\
\hline 3 & 8775486 & CRELD1 & ASD; AVSD & 14 & 20167619 & LOC100506393 & TOF; PA; VSD; ASD \\
\hline 3 & 196466728 & PAK2 & ASD; PS; PDA & 15 & 20737094 & GOLGA6L6 & TGA; ASD \\
\hline 4 & 53227 & ZNF595 & PS; ASD; VSD; HLHS & 15 & 22051853 & POTEB & TOF; VSD; ASD \\
\hline 4 & 1005760 & FGFRL1 & ASD; VSD; TGA & 15 & 22546565 & REREP3 & TOF; VSD; ASD; TGA \\
\hline 4 & 89178761 & PPM1K & ASD; TOF & 15 & 22833395 & CYFIP1 & $\begin{array}{l}\text { CoA; VSD; ASD; TOF; CAT; } \\
\text { TAPVR }\end{array}$ \\
\hline 4 & 91048684 & CCSER1 & ASD; PDA; CoA & 15 & 32322686 & CHRNA7 & ASD; PDA; PS; HET \\
\hline 4 & 135117489 & PABPC4L & TOF; TGA; PDA & 15 & 55495164 & RAB27A & COA; AS; HLHS \\
\hline 4 & 174447652 & HAND2 & ASD; VSD; PS; TOF & 15 & 100106133 & MEF2A & HLHS; VSD; ASD; AVSD; PS \\
\hline 5 & 659977 & TPPP & HEART; ASD; TOF & 16 & 3775056 & CREBBP & ASD; PFO; PDA \\
\hline 5 & 37812779 & GDNF & PDA; ASD & 16 & 15806751 & MYH11 & ASD; VSD \\
\hline 5 & 70330951 & GTF2H2 & HEART; TOF; ASD & 16 & 30097115 & TBX6 & ASD; VSD; CoA \\
\hline 5 & 172659107 & NKX2-5 & ASD; AVB; EBS & 16 & 86544133 & FOXC2 & HLHS; IAA; AVSD; PA; LSVC \\
\hline 5 & 176513921 & FGFR4 & PDA; VSD & 17 & 19281774 & MAPK7 & ASD; VSD; HLHS; HEART \\
\hline 6 & 292101 & DUSP22 & ASD & 17 & 17584787 & AATF & HEART; ASD; AVSD \\
\hline 6 & 149639436 & TAB2 & ASD, VSD, PS, AS, CM & 17 & 44107282 & KANSL1 & ASD; VSD; PDA; PS \\
\hline 6 & 161768590 & PARK2 & TOF; HLHS; AS & 17 & 59477257 & TBX2 & ASD; PDA; BAV \\
\hline 6 & 168707584 & DACT2 & TOF; ASD; VSD & 18 & 580369 & CETN1 & AS; TOF; HEART \\
\hline 7 & 64864053 & ZNF92 & VSD; TOF; PS & 20 & 13976146 & MACROD2 & TGA; ASD \\
\hline 7 & 73442427 & ELN & SVPS; SVAS; VSD & 21 & 28208606 & ADAMTS1 & AVSD; PS; AS \\
\hline 7 & 88388753 & ZNF804B & CoA; TOF; SV & 21 & 36160098 & RUNX1 & AVSD; PA; TGA \\
\hline 7 & 110303106 & IMMP2L & TOF; TA;PS & 22 & 19744226 & TBX1 & CAT; TOF; VSD; CoA; DORV \\
\hline 7 & 132469623 & $\mathrm{CHCHD} 3$ & AS; CoA; VSD & 22 & 21353326 & CRKL & TOF; ASD; VSD \\
\hline 7 & 143970523 & ARHGEF34P & TGA; TOF; PA & 22 & 22113947 & MAPK1 & CAT; TA; TOF \\
\hline 8 & 385585 & FBXO25 & HEART; VSD & 22 & 22311403 & TOP3В & TOF; AS \\
\hline 8 & 7272385 & DEFB4B & HEART; VSD; ASD; AVSD & 22 & 25747385 & LRP5L & TOF; ASD \\
\hline 8 & 11561717 & GATA4 & TOF; AVSD; VSD; BSVC & 22 & 29999545 & NF2 & PS; VSD \\
\hline 8 & 61591324 & CHD7 & ASD, AVSD, IAA & $\mathrm{x}$ & 585079 & SHOX & CoA; AS \\
\hline 9 & 214865 & DOCK8 & TOF; ASD; VSD & $\mathrm{x}$ & 7866804 & PNPLA4 & VSD; HEART; BAV \\
\hline 9 & 504695 & KANK1 & TOF; PS & & & & \\
\hline
\end{tabular}

Shown are the chromosome (Chrom) and approximate genetic location (Genome Reference Consortium Human Build 37 [GRCh37/hg19]), a gene within the minimal region of overlap and the observed spectrum of heart defects. Genes that have been previously identified with coding sequence mutations in patients with congenital cardiac defects are in red text; those determined to have a role in heart development based on an animal model (but without identified sequence variants in patients with heart defects) are in blue. Each locus spans multiple genes, and the location and listed gene are only intended to provide a landmark for the candidate interval. The boundaries of the critical region can be derived from the individual cases presented in Supporting Information Table S1. Heart defects listed include coarctation of the aorta (CoA), interrupted aortic arch (IAA), hypoplastic left heart syndrome (HLHS), atrial and ventricular septal defects (ASDs and VSDs), atrioventricular septal defect (AVSD), tetralogy of FALLOT (TOF), double outlet right ventricle (DORV), bicuspid aortic valve (BAV), truncus arteriosus (CAT), situs inversus (SI), heterotaxy (HET), supravalvar aortic and pulmonary stenosis (SVAS and SVPS), aortic stenosis or insufficiency (AS or AI), pulmonary stenosis or insufficiency (PS or PI), tricuspid stenosis or regurgitation (TS or TR), mitral stenosis or regurgitation (MS or MR), total or partial anomalous venous return (TAPVR or PAPVR), tricuspid atresia (TA), pulmonary atresia (PA), patent ductus arteriosus (PDA), left or bilateral superior vena cava (LSVC or BSVC), cardiomyopathy and left ventricular noncompaction (CM and LVNC), and Ebstein's anomaly (EBS). If the heart defect was not described, then "HEART" is listed.

ment but have not previously been implicated in causing human CHDs. These included imbalances involving ETS1, HES4, MEF2A, MTHFR, TBX2, or TBX6 in five or more patients (Table 1).

\section{Relative Risk of Congenital Cardiac Defects for Each Candidate Region}

One of the major limitations of relying on database reporting for this type of analysis is the inability to assess risk of developing a cardiovascular abnormality if a particular gene or genetic region is involved in a chromosomal imbalance. To address this, we reviewed a large dataset of patients tested at a clinical microarray laboratory (Signature Genomics Inc., Spokane, WA, USA), which includes those reported by Cooper et al. ${ }^{13}$ From that dataset, a rough estimate could be obtained of the relative risk of a CHD when a specific gene was involved in a chromosomal imbalance by comparing the gain or loss of that gene in a population of patients with known or suspected cardiac defects referred for copy number analysis com- 
pared with a healthy control population. This analysis was performed for the 79 loci noted to be involved in chromosomal copy number variations in at least five patients.

For 66 of the 79 loci involved in chromosomal imbalances in five or more cases with CHD, the incidence of deletions and duplications in a control population of 8329 individuals without known CHDs was available. A total of 36 of these 66 loci were noted to have a significantly increased risk of CHDs compared with control when involved in a chromosomal duplication and/or deletion (Table 2). As noted above, 11 of the loci (including loci containing the ELN, HAND2, GATA4, GFA5, and $T B X 1)$ demonstrated significant elevations in CHD risk when the locus was duplicated and when it was deleted while the remaining 25 only achieved significance for a duplication or a deletion. For many loci, there were not enough occurrences of a duplication or deletion to calculate a meaningful statistic for that type of imbalance. Given the rarity of chromosomal loss or gain in the healthy population, it was difficult to exclude any of the identified loci as definitively not being associated with an increased risk of CHD with a gain or a loss. However, frequent chromosomal imbalances of loci on chromosome $7 \mathrm{q} 31.1$ (which includes IMMPL2) and on chromosome 6q26 (which includes $P A R K 2$ ) in the control population makes their involvement in CHD pathogenesis unlikely. Furthermore, several loci were only reported from a single database raising the possibility that the

Table 2. Incidence of Reported Congenital Heart Defects in Patients with Chromosomal Imbalances Involving Selected Candidate Genes

\begin{tabular}{lcclll}
\hline & \multicolumn{2}{l}{ Signature Genomics } & & \multicolumn{2}{l}{} \\
\cline { 2 - 3 } & \multicolumn{2}{l}{ Cooper et al. ${ }^{13}$} & & DECIPHER \\
\cline { 5 - 6 } \cline { 5 - 6 } & Deletion & Duplication & & Deletion & Duplication \\
\hline GATA4 & $9 / 21$ & $5 / 29$ & & $11 / 11$ & $2 / 8$ \\
NOTCH1 & $6 / 12$ & $2 / 15$ & & $2 / 4$ & $1 / 6$ \\
TBX1 & $88 / 324$ & $15 / 172$ & & $6 / 15$ & $5 / 22$ \\
GJA5 & $11 / 122$ & $7 / 115$ & & $1 / 27$ & $6 / 27$ \\
JAG1 & $1 / 2$ & $1 / 6$ & & $2 / 2$ & $1 / 2$ \\
CRELD1 & $1 / 12$ & $2 / 13$ & & $2 / 10$ & $2 / 3$ \\
CHRNA7 & $3 / 125$ & $20 / 257$ & & $1 / 32$ & $2 / 34$ \\
HEY1 & $0 / 2$ & $0 / 3$ & & $2 / 2$ & $0 / 1$ \\
HEY2 & $1 / 9$ & $0 / 2$ & & $1 / 4$ & $0 / 0$ \\
ATRNL1 & $1 / 3$ & $0 / 8$ & & $5 / 7$ & $0 / 0$ \\
KANSL1 & $8 / 47$ & $1 / 10$ & & $2 / 18$ & $0 / 9$ \\
\hline
\end{tabular}

All cases in the signature dataset and DECIPHER databases that involved the candidate gene were examined; shown are the number of cases with reported congenital cardiac defects over the total number of cases. Color coding of genes is as described for Table 1. Note that, even for genes such as TBX1 that have been clearly linked to congenital heart defects, chromosomal imbalances involving those genes result in clinically recognized cardiac defects in only a subset of cases. assignment of a chromosomal imbalance was an artifact of the testing format. In fact, this single data source artifact might account for six of the 12 loci for which imbalances were noted in five or more CHD cases, but no incidence data were available. These loci are also unlikely to be involved in CHD pathogenesis.

Other genes previously implicated in CHD pathogenesis, including the NOTCH1, TAB2, and CHD7 genes, were more frequently involved in chromosomal imbalances in patients with CHD than in controls. In general, genes determined to be important for cardiac development were not commonly involved in chromosomal imbalances and when imbalances do occur they are commonly associated with congenital cardiac defects. Therefore, a complementary approach to assessing risk of $\mathrm{CHD}$ is to estimate penetrance of CHD in individuals with a gain or loss of a specific gene or locus (Table 3). Deletions of GATA4 were noted to be associated with congenital cardiac defects in $9 / 21$ patients in the Signature dataset $^{13}$ and $11 / 11$ patients in the DECIPHER database. Interestingly, deletions involving TBX1 resulted in reported cardiac abnormalities in 27\% of the patients in the Signature dataset and in $40 \%$ of the patients in the DECIPHER database. This is comparable with the previously reported rate of cardiovascular abnormalities (approximately $25 \%$ ) in patients with DiGeorge syndrome. ${ }^{18}$ Chromosomal imbalances involving NOTCH1, which has been demonstrated to be responsible for cardiac defects in some families, ${ }^{19}$ are also associated with an elevated risk of CHDs. The incidence of reported cardiac defects in patients with deletions of NOTCH1 is approximately $50 \%$ based on the datasets from DECIPHER and from the Signature database. ${ }^{13}$ Therefore, the frequency with which a chromosomal deletion involving a gene known to be involved in heart development results in a congenital cardiac defect varies and the penetrance is usually incomplete suggesting that other factors, either genetic or environmental, may be important for chromosomal imbalances to cause clinically significant congenital heart disease.

\section{Refinement of Candidate Loci for CHD}

How the data in the databases can be used to restrict the candidate regions for novel genes involved in human heart development and the pathogenesis of CHD is demonstrated with the following examples. 
Table 3. Comparison of the Frequency of Observed Chromosomal Imbalances in Individuals with Congenital Heart Defects $(\mathrm{n}=1964)$ Compared with Controls $(\mathrm{n}=8329)$

\begin{tabular}{|c|c|c|c|c|c|c|}
\hline Gene & CHD Deletions & Control Deletions & $P$ value & CHD Duplications & Control Duplications & $P$ value \\
\hline AATF & $3 / 1964$ & 2/8329 & .051 & 3/1964 & $3 / 8329$ & .09 \\
\hline ADAMTS1 & $1 / 1964$ & $0 / 8329$ & .19 & 8/1964* & $0 / 8329$ & $<.0001$ \\
\hline ARHGEF5 & $4 / 1964$ & $0 / 8329$ & .001 & $1 / 1964$ & $0 / 8329$ & .19 \\
\hline ATRNL1 & $0 / 1964$ & $8 / 8329$ & .37 & $0 / 1964$ & $0 / 8329$ & N/A \\
\hline BMPR1A & $0 / 1964$ & $0 / 8329$ & N/A & $0 / 1964$ & $1 / 8329$ & 1.00 \\
\hline CCSER1 & 0/1964 & 2/8329 & 1.00 & $1 / 1964$ & $4 / 8329$ & 1.0 \\
\hline CETN1 & $5 / 1964$ & $1 / 8329$ & .001 & $13 / 1964 \dagger$ & $6 / 8329$ & $<.0001$ \\
\hline $\mathrm{CHCHD} 3$ & $4 / 1964$ & $0 / 8329$ & .001 & $1 / 1964$ & $0 / 8329$ & .19 \\
\hline CHD7 & $2 / 1964$ & $0 / 8329$ & .04 & 0/1964 & $0 / 8329$ & N/A \\
\hline CHRNA7 & $3 / 1964$ & $4 / 8329$ & .13 & $17 / 1964$ & $58 / 8329$ & .43 \\
\hline CIR1 & $1 / 1964$ & $0 / 8329$ & .19 & $1 / 1964$ & $0 / 8329$ & .19 \\
\hline CNTN6 & 2/1964 & 4/8329 & .32 & 6/1964 & $19 / 8329$ & .61 \\
\hline CREBBP & 2/1964 & $1 / 8329$ & .10 & $1 / 1964$ & $7 / 8329$ & 1 \\
\hline CRELD1 & $1 / 1964$ & $1 / 8329$ & .35 & $1 / 1964$ & $0 / 8329$ & .19 \\
\hline CRKL & $46 / 1964$ & $1 / 8329$ & $<.0001$ & $15 / 1964$ & $8 / 8329$ & $<.0001$ \\
\hline CYP2E1 & $4 / 1964$ & $6 / 8329$ & .11 & $70 / 1964$ & $177 / 8329$ & .0002 \\
\hline DACT2 & $1 / 1964$ & $0 / 8329$ & .19 & 0/1964 & $0 / 8329$ & $N / A$ \\
\hline DOCK8 & 3/1964 & $6 / 8329$ & .39 & $13 / 1964$ & 29/8329 & .0498 \\
\hline DUSP22 & 189/1964 & $27 / 8329$ & $<.0001$ & $219 / 1964$ & $2 / 8329$ & $<.0001$ \\
\hline EHMT1 & $3 / 1964$ & $3 / 8329$ & .09 & $3 / 1964$ & $0 / 8329$ & .01 \\
\hline ELN & $14 / 1964$ & $0 / 8329$ & $<.0001$ & $2 / 1964$ & $0 / 8329$ & .04 \\
\hline ETS1 & $11 / 1964$ & $0 / 8329$ & $<.0001$ & $1 / 1964$ & $0 / 8329$ & .19 \\
\hline FBXO25 & $5 / 1964$ & $4 / 8329$ & .02 & 2/1964 & $2 / 8329$ & .17 \\
\hline FGFR4 & 0/1964 & 0/8329 & $\mathrm{N} / \mathrm{A}$ & 2/1964 & $0 / 8329$ & .04 \\
\hline FGFRL1 & $4 / 1964$ & $5 / 8329$ & .07 & $1 / 1964$ & $1 / 8329$ & .35 \\
\hline FOXF1 & $1 / 1964$ & $0 / 8329$ & .19 & $1 / 1964$ & $0 / 8329$ & .19 \\
\hline FSHR & $1 / 1964$ & $2 / 8329$ & .47 & $0 / 1964$ & $1 / 8329$ & 1.00 \\
\hline GATA4 & $7 / 1964$ & $0 / 8329$ & $<.0001$ & $4 / 1964$ & $0 / 8329$ & .001 \\
\hline GDNF & $0 / 1964$ & $1 / 8329$ & 1.000 & 2/1964 & $3 / 8329$ & .24 \\
\hline GJA5 & 6/1964 & 2/8329 & .001 & 6/1964 & $3 / 8329$ & .002 \\
\hline HAND2 & $5 / 1964$ & $0 / 8329$ & $<.0001$ & 2/1964 & $0 / 8329$ & .04 \\
\hline HES4 & $5 / 1964$ & $1 / 8329$ & .001 & $1 / 1964$ & $0 / 8329$ & .19 \\
\hline IMMP2L & $15 / 1964$ & $47 / 8329$ & .3 & 0/1964 & $5 / 8329$ & 1.00 \\
\hline KANK1 & $9 / 1964$ & $29 / 8329$ & .47 & $9 / 1964$ & $9 / 8329$ & .003 \\
\hline KANSL1 & 0/1964 & 0/8329 & $\mathrm{N} / \mathrm{A}$ & $1 / 1964$ & $0 / 8329$ & 19 \\
\hline LOC100506393 & 0/1964 & 2/8329 & 1.00 & 3/1964 & $0 / 8329$ & .01 \\
\hline MACROD2 & $10 / 1964$ & $8 / 8329$ & .001 & 2/1964 & $0 / 8329$ & .04 \\
\hline MAPK1 & $2 / 1964$ & $1 / 8329$ & .10 & $4 / 1964$ & $0 / 8329$ & .001 \\
\hline MAPK7 & $0 / 1964$ & $0 / 8329$ & N/A & $1 / 1964$ & $0 / 8329$ & .19 \\
\hline MEF2A & $0 / 1964$ & $1 / 8329$ & 1.00 & $2 / 1964$ & $1 / 8329$ & .10 \\
\hline MTHFR & $2 / 1964$ & $0 / 8329$ & .04 & 0/1964 & $0 / 8329$ & N/A \\
\hline MYH11 & 0/1964 & 3/8329 & 1.00 & $4 / 1964$ & $12 / 8329$ & .53 \\
\hline NF2 & 0/1964 & $0 / 8329$ & N/A & 2/1964 & $0 / 8329$ & .04 \\
\hline NKX2-5 & 0/1964 & $0 / 8329$ & N/A & $1 / 1964$ & $0 / 8329$ & .19 \\
\hline NKX6-2 & $0 / 1964$ & $0 / 8329$ & N/A & $4 / 1964$ & $2 / 8329$ & .01 \\
\hline $\mathrm{NOTCH} 1$ & $4 / 1964$ & 3/8329 & .03 & $1 / 1964$ & $1 / 8329$ & .35 \\
\hline NPHP1 & 10/1964 & $36 / 8329$ & .65 & 23/1964 & $32 / 8329$ & .01 \\
\hline PABPC4L & $8 / 1964$ & 22/8329 & .29 & $2 / 1964$ & $0 / 8329$ & .04 \\
\hline PAK2 & 0/1964 & $0 / 8329$ & $\mathrm{~N} / \mathrm{A}$ & 3/1964 & $0 / 8329$ & .01 \\
\hline PARK2 & $5 / 1964$ & $24 / 8329$ & .8 & $8 / 1964$ & $29 / 8329$ & .69 \\
\hline PPM1K & 0/1964 & $0 / 8329$ & N/A & 0/1964 & $0 / 8329$ & N/A \\
\hline PRRX1 & $1 / 1964$ & $0 / 8329$ & .19 & 0/1964 & $0 / 8329$ & N/A \\
\hline RAB27A & 0/1964 & 2/8329 & 1.00 & 0/1964 & $1 / 8329$ & 1.00 \\
\hline RGPD4 & 0/1964 & $1 / 8329$ & 1.00 & $1 / 1964$ & $0 / 8329$ & .19 \\
\hline RUNX1 & $1 / 1964$ & $2 / 8329$ & .47 & $8 / 1964^{\star}$ & $1 / 8329$ & $<.0001$ \\
\hline SLC16A7 & 0/1964 & $2 / 8329$ & 1.00 & 0/1964 & $1 / 8329$ & 1.00 \\
\hline SMYD3 & $5 / 1964$ & $1 / 8329$ & .001 & 2/1964 & $3 / 8329$ & .24 \\
\hline TAB2 & $2 / 1964$ & $0 / 8329$ & .04 & $0 / 1964$ & $0 / 8329$ & N/A \\
\hline TBX1 & 49/1964 & $5 / 8329$ & $<.0001$ & 10/1964 & $7 / 8329$ & $<.0001$ \\
\hline TBX2 & $1 / 1964$ & 0/8329 & .19 & $1 / 1964$ & $0 / 8329$ & .19 \\
\hline TBX6 & $2 / 1964$ & $3 / 8329$ & .24 & $3 / 1964$ & $2 / 8329$ & .051 \\
\hline TPPP & $5 / 1964$ & $4 / 8329$ & .02 & $4 / 1964$ & $17 / 8329$ & 1.0 \\
\hline TUBGCP5 & $15 / 1964$ & $22 / 8329$ & .001 & $16 / 1964$ & $36 / 8329$ & .03 \\
\hline ZNF595 & 4/1964 & $0 / 8329$ & .001 & $5 / 1964$ & $3 / 8329$ & .01 \\
\hline ZNF804B & $3 / 1964$ & $0 / 8329$ & .01 & $1 / 1964$ & $5 / 8329$ & 1.0 \\
\hline ZNF92 & $14 / 1964$ & $52 / 8329$ & .66 & $8 / 1964$ & $13 / 8329$ & .04 \\
\hline
\end{tabular}

${ }^{*}$ All with trisomy 21

†11 out of 13 with trisomy 18 .

For each candidate region, the percentage of deletions and duplications that was associated with a reported cardiac defect was recorded. To determine if the observed difference between the CHD and control populations was statistically significant, a Wilcoxon signed-rank test was used. Statistically significant $P$ values are represented in bold.

ND: ALG10; AMY2A; ANTXRL; DEFB4B; GOLGA6L6; GTF2H2; LOC6464813; LRP5L; POTEB; PNPLA4; REREP3; SHOX; TOP3B. 


\section{Locus at Iq24.2}

In the databases, we identified seven individuals with deletions involving 1q24.2. The heart defects were variable but included VSD (3 patients), patent foramen ovale ( $\mathrm{PFO} ; 2$ patients), heart defect not otherwise specified (1 patient) and ECG abnormality (1 patient) (Table 4A). We identified a primary critical region (CR), where the proximal and distal boundaries were each determined by a single case, that included nine genes. A secondary CR, defined by allowing the exclusion of single cases, included additional genes. None of the genes within the primary and secondary CRs has a known role in heart development or the pathogenesis of congenital cardiac defects. Although a risk calculation could not be performed using a gene (PRRX1) within the primary CR, the absence of chromosomal imbalances involving this region in healthy controls supports its potential role in CHD pathogenesis.

\section{Locus at $2 q 31.1$}

Fourteen individuals with deletions (12 patients) or duplications ( 2 patients) involving $2 \mathrm{q} 31.1$ were identified (Table 4B). The heart defects were primarily septal defects including VSD ${ }^{6}$ and ASD. ${ }^{3}$ The primary CR contained six genes with a secondary CR containing another 2. Within the primary CR is the gene encoding for CIR 1 that has been reported to regulate the Notch signaling pathway and to be abundantly expressed in the heart ${ }^{20}$ and the gene encoding for the SP3 transcription factor, which has been demonstrated in a mouse model to have an important role in heart development. ${ }^{21}$ There was one case (Wiki389) in which the deletion did not significantly overlap with two other deletions in the region suggesting that (1) there is another cardiac gene located more proximally on chromosome 2, (2) there is an effect of the deletion on nearby genes, or (3) the deletion, in that case, is not directly responsible for the observed cardiac defect. Although a risk calculation could not be performed using a gene (CIR1) within the primary CR, the absence of chromosomal imbalances involving this region in healthy controls again supports its potential role in CHD pathogenesis.

\section{Locus at $15 q 26.3$}

Thirteen individuals with deletions (9 patients) or duplications (4 patients) involving $15 \mathrm{q} 26.3$ were identified (Table 4C). A broad range of cardiac defects were noted but some less common heart defects appeared to be overrepresented including hypoplastic left heart syndrome (HLHS) in 3.
$\mathrm{CoA}$ and ventricular septal defects were also relatively common. Of the genes in the primary and secondary CRs, the gene encoding the MEF2A transcription factor is an important candidate based on its high level of expression in the developing heart in animal models. ${ }^{22}$

\section{DiGeorge Syndrome Region}

Previous studies have noted that mutation affecting TBX1 in human patients ${ }^{23}$ or the targeted depletion of $T b x 1$ in animal models ${ }^{24-26}$ can reproduce many of the cardiac manifestations of DiGeorge syndrome including the development of conotruncal-type CHDs. However, it has also been noted that chromosomal imbalances involving chromosome $22 \mathrm{q} 11$ but not including TBX1 can also be associated with heart defects. ${ }^{27,28}$ Therefore, we examined the cases within the databases to determine if there was evidence that multiple genes on chromosome $22 \mathrm{q} 11$ might be involved in cardiac defects. We identified 85 chromosomal imbalances involving chromosome $22 \mathrm{q} 11$ in the database. Seventy-eight of the 85 involved at least one of three genes, TBX1, CRKL, and $M A P K 1$, previously determined or suspected to have a role in human heart development and in the pathogenesis of CHDs. Of these, seven involved chromosomal imbalance of TBX1 alone, 35 involved TBX1 and CRKL, eight involved CRKL alone, four involved both CRKL and $M A P K 1$, and 19 involved MAPK1 alone (Table 5). Small $(<300 \mathrm{~kb})$ chromosomal imbalances involving chromosome 22q11 distal to MAPK1 were noted in six patients from one database, but these may reflect nonpathogenic rearrangements or uncertain $\mathrm{CNV}$ ascertainment based on a single testing format.

\section{Discussion}

\section{General Approach}

Identification of the causes of CHDs has proved to be a challenging task. The underlying genetic abnormality responsible for a cardiac defect is known in only a very small minority of patients. Characterization of patients with chromosomal imbalances and associated congenital cardiac abnormalities is an attractive approach to identifying disease genes that has been successful in identifying ELN (elastin), TBX1 and GATA4 as genes involved in the pathogenesis of congenital cardiac defects. Unfortunately, there are currently a number of obstacles to this approach. Perhaps, most importantly is the lack of a centralized, 
Table 4. Genes Contained within the Critical Regions for Three Loci

Table 4A. Critical Region on Chromosome 1q24.2 with Surrounding Genes. None of the Genes in the Primary or Secondary Critical Regions Are Strongly Implicated in Heart Development

\begin{tabular}{|c|c|c|c|c|c|c|c|}
\hline & $\begin{array}{l}\text { D } 262739 \\
\text { DEL } \\
\text { ECG ABNL }\end{array}$ & $\begin{array}{l}\text { D } 253856 \\
\text { DEL } \\
\text { HEART }\end{array}$ & $\begin{array}{l}\text { D } 2572 \\
\text { DEL } \\
\text { VSD }\end{array}$ & $\begin{array}{l}\text { W } 1505 \\
\text { DEL } \\
\text { VSD }\end{array}$ & $\begin{array}{l}\text { W } 1506 \\
\text { DEL } \\
\text { PFO/PDA }\end{array}$ & $\begin{array}{l}\text { W } 1546 \\
\text { DEL } \\
\text { PFO }\end{array}$ & $\begin{array}{l}\text { I nssv577229 } \\
\text { DEL } \\
\text { VSD }\end{array}$ \\
\hline TBX19 & $x$ & $x$ & & $x$ & $x$ & $x$ & $x$ \\
\hline XCL2 & $x$ & $x$ & & $\mathrm{X}$ & $x$ & $\mathrm{X}$ & $x$ \\
\hline $\mathrm{XCL1}$ & $x$ & $x$ & & $x$ & $x$ & $x$ & $x$ \\
\hline DPT & $x$ & $x$ & & $x$ & $x$ & $x$ & $x$ \\
\hline ATP1B & $\mathrm{X}$ & $x$ & & $\mathrm{X}$ & $\mathrm{X}$ & $\mathrm{X}$ & $\mathrm{X}$ \\
\hline NME7 & $\mathrm{X}$ & $x$ & & $x$ & $x$ & $x$ & $x$ \\
\hline SLC19A2 & $x$ & $x$ & & $x$ & $x$ & $x$ & $x$ \\
\hline SELP & $x$ & $x$ & & $\mathrm{X}$ & $x$ & $x$ & $\mathrm{X}$ \\
\hline METTL18 & $X$ & $X$ & $X$ & $X$ & $x$ & $x$ & $\mathrm{X}$ \\
\hline SELL & $x$ & $x$ & $x$ & $x$ & $x$ & $x$ & $x$ \\
\hline SELE & $\mathrm{X}$ & $\mathrm{X}$ & $\mathrm{X}$ & $x$ & $x$ & $x$ & $x$ \\
\hline KIFAP3 & $\mathrm{X}$ & $\mathrm{X}$ & $\mathrm{X}$ & $x$ & $\mathrm{X}$ & $\mathrm{X}$ & $\mathrm{X}$ \\
\hline GORAB & $x$ & $\mathrm{X}$ & $x$ & $\mathrm{X}$ & $x$ & $x$ & $x$ \\
\hline PRRX1 & $x$ & $\mathrm{x}$ & $x$ & $\mathrm{X}$ & $x$ & $x$ & $x$ \\
\hline FMO3 & $\mathrm{X}$ & $\mathrm{X}$ & $\mathrm{X}$ & $\mathrm{X}$ & $\mathrm{x}$ & $\mathrm{X}$ & $\mathrm{X}$ \\
\hline FMO2 & $\mathrm{X}$ & $\mathrm{x}$ & $\mathrm{X}$ & $\mathrm{X}$ & $\mathrm{X}$ & $x$ & $x$ \\
\hline FMO1 & $x$ & $x$ & $x$ & $x$ & $x$ & $x$ & $x$ \\
\hline PRRC2C & $x$ & & $x$ & $x$ & $x$ & $x$ & $x$ \\
\hline VAMP4 & $\mathrm{x}$ & & $\mathrm{X}$ & $x$ & $x$ & $\mathrm{x}$ & $x$ \\
\hline METTL13 & $x$ & & $x$ & $x$ & $x$ & $x$ & $x$ \\
\hline DNM3 & $x$ & & $x$ & $x$ & $x$ & $x$ & $x$ \\
\hline PIGC & & & $X$ & $X$ & $X$ & $X$ & $X$ \\
\hline FASLG & & & $\mathrm{X}$ & $x$ & $\mathrm{X}$ & $\mathrm{X}$ & $X$ \\
\hline TNSF18 & & & $x$ & $x$ & $\mathrm{X}$ & $x$ & $x$ \\
\hline
\end{tabular}

Table 4B. Critical Region on Chromosome 2q31.1 with Surrounding Genes. SP3 and CIR1 Have Been Determined to Have a Role in Vertebrate Heart Development in Animal Models.

\begin{tabular}{|c|c|c|c|c|c|c|c|c|c|c|c|c|c|c|}
\hline & $\begin{array}{l}\text { W } 1476 \\
\text { DEL } \\
\text { VSD; } \\
\text { PS }\end{array}$ & $\begin{array}{l}\text { W } 1475 \\
\text { DEL } \\
\text { ASD }\end{array}$ & $\begin{array}{l}\text { DEL } \\
\text { ASD; } \\
\text { PDA }\end{array}$ & W 1481 & W 1501 & $\begin{array}{l}\text { DEL } \\
\text { VSD }\end{array}$ & $\begin{array}{l}\text { DEL } \\
\text { Ao }\end{array}$ & $\begin{array}{l}\text { DEL } \\
\text { MS; MR }\end{array}$ & $\begin{array}{l}\text { DEL } \\
\text { VSD }\end{array}$ & $\begin{array}{l}\text { DEL } \\
\text { ASD; } \\
\text { PDA }\end{array}$ & $\begin{array}{l}\text { DEL } \\
\text { VSD; } \\
\text { DORV; } \\
\text { PS }\end{array}$ & $\begin{array}{l}\text { I } \\
\text { nssv577738 } \\
\text { DEL } \\
\text { HEART }\end{array}$ & $\begin{array}{l}\text { C } \\
9900015 \\
\text { DUP } \\
\text { HEART }\end{array}$ & $\begin{array}{l}\text { D } \\
258540 \\
\text { DUP } \\
\text { HEART }\end{array}$ \\
\hline PDK1 & & & $\mathrm{x}$ & $x$ & $x$ & $x$ & $x$ & $x$ & $x$ & & & & $x$ & $x$ \\
\hline RAPGEF4 & & & $\mathrm{X}$ & $x$ & X & $X$ & $x$ & $x$ & $x$ & & & & $x$ & $x$ \\
\hline ZAK & X & X & $x$ & X & X & $\mathrm{x}$ & X & X & X & X & X & & $x$ & $x$ \\
\hline CDCA7 & $x$ & $x$ & $\mathrm{x}$ & $x$ & $x$ & $x$ & $\mathrm{X}$ & $x$ & X & $x$ & X & & $x$ & $x$ \\
\hline SP3 & X & X & $\mathrm{X}$ & X & X & X & X & & X & X & X & X & X & X \\
\hline OLA1 & $x$ & $\mathrm{x}$ & $\mathrm{x}$ & $x$ & $x$ & $\mathrm{X}$ & $x$ & & $x$ & $x$ & X & $X$ & $x$ & $x$ \\
\hline CIR1 & $x$ & $x$ & $\hat{x}$ & $x$ & $x$ & $x$ & $x$ & & $x$ & $x$ & $x$ & $x$ & $x$ & $x$ \\
\hline SCRN3 & $x$ & $x$ & $x$ & $x$ & $x$ & $x$ & $x$ & & $x$ & $x$ & X & $x$ & $x$ & $x$ \\
\hline GPR155 & $x$ & $x$ & $\mathrm{X}$ & $x$ & $x$ & $X$ & $x$ & & $x$ & X & $x$ & $X$ & $x$ & $x$ \\
\hline WIPF1 & $x$ & $x$ & $x$ & $x$ & $x$ & $x$ & $x$ & & $x$ & $x$ & $x$ & $x$ & $x$ & $x$ \\
\hline CHRNA1 & & X & $X$ & X & X & X & X & & X & X & & X & X & X \\
\hline $\mathrm{CHN} 1$ & & $x$ & $\mathrm{x}$ & $x$ & X & $x$ & $x$ & & $x$ & $x$ & & $x$ & $x$ & $x$ \\
\hline
\end{tabular}

Table 4C. Critical Region on Chromosome 15q26.3 with Surrounding Genes. MEF2A Has Been Determined to Have a Role in Vertebrate Heart Development in Animal Models

\begin{tabular}{|c|c|c|c|c|c|c|c|c|c|c|c|c|c|}
\hline & $\begin{array}{l}\text { W } 1338 \\
\text { DEL } \\
\text { HLHS; } \\
\text { CoA; } \\
\text { VSD }\end{array}$ & $\begin{array}{l}\text { D } 251099 \\
\text { DEL } \\
\text { CoA; } \\
\text { VSD }\end{array}$ & $\begin{array}{l}\text { D } 270050 \\
\text { DEL } \\
\text { VSD }\end{array}$ & $\begin{array}{l}\text { W } 1314 \\
\text { DEL } \\
\text { AVSD }\end{array}$ & $\begin{array}{l}\text { W } 1313 \\
\text { DEL } \\
\text { ASD; } \\
\text { PS }\end{array}$ & $\begin{array}{l}\text { W } 3 \\
\text { DEL } \\
\text { HLHS }\end{array}$ & $\begin{array}{l}\text { W } 5 \\
\text { DEL } \\
\text { HLHS; } \\
\text { VSD }\end{array}$ & $\begin{array}{l}\text { W } 1525 \\
\text { DEL } \\
\text { VSD }\end{array}$ & $\begin{array}{l}\text { D } 259934 \\
\text { DEL } \\
\text { VSD }\end{array}$ & $\begin{array}{l}\text { C } 9902150 \\
\text { DUP } \\
\text { HEART }\end{array}$ & $\begin{array}{l}\text { D } 256144 \\
\text { DUP } \\
\text { ASD }\end{array}$ & $\begin{array}{l}\text { D } 256144 \\
\text { DUP } \\
\text { ASD }\end{array}$ & $\begin{array}{l}\text { I nssv582685 } \\
\text { DUP } \\
\text { HEART }\end{array}$ \\
\hline NR2F2 & $x$ & $x$ & & $X$ & & $x$ & $x$ & & $x$ & $x$ & $x$ & $x$ & \\
\hline ARRDC4 & $x$ & $x$ & & $x$ & & $x$ & $x$ & $x$ & $x$ & $x$ & $x$ & $x$ & \\
\hline IGF1R & $x$ & $x$ & & $x$ & $x$ & $x$ & $x$ & $x$ & $x$ & $x$ & $x$ & $x$ & \\
\hline SYNM1 & $x$ & $x$ & & $x$ & $x$ & $x$ & $x$ & $x$ & $x$ & $x$ & $x$ & $x$ & \\
\hline TTC23 & $x$ & $x$ & X & $x$ & $\mathrm{X}$ & $\mathrm{X}$ & $x$ & $\mathrm{X}$ & $\mathrm{X}$ & $x$ & $\mathrm{X}$ & $\mathrm{X}$ & \\
\hline LRRC28 & $x$ & $x$ & $x$ & $x$ & $x$ & $x$ & $x$ & $x$ & $x$ & $x$ & $x$ & $x$ & $x$ \\
\hline MEF2A & $x$ & $x$ & $x$ & $x$ & $x$ & $x$ & $x$ & $x$ & $x$ & $x$ & $x$ & $x$ & $x$ \\
\hline LYSMD4 & $x$ & $x$ & $x$ & $x$ & $x$ & $x$ & $x$ & $x$ & $x$ & $x$ & $x$ & $x$ & $x$ \\
\hline DNM1P & $x$ & $x$ & $x$ & $x$ & $x$ & $x$ & $x$ & $\mathrm{X}$ & $x$ & $x$ & $\mathrm{x}$ & $\mathrm{X}$ & $\mathrm{X}$ \\
\hline ADAMTS17 & $x$ & $x$ & $x$ & $x$ & $x$ & $x$ & $x$ & $x$ & $x$ & $x$ & $x$ & $x$ & $x$ \\
\hline CERS3 & $x$ & $x$ & $x$ & $x$ & $x$ & $x$ & $x$ & $x$ & $x$ & $x$ & $x$ & $x$ & $x$ \\
\hline LINS1 & $x$ & $x$ & $x$ & $x$ & $x$ & $x$ & $x$ & $\mathrm{X}$ & $\mathrm{X}$ & $x$ & $x$ & $\mathrm{X}$ & $x$ \\
\hline ASB7 & $x$ & $x$ & $x$ & $x$ & $x$ & $x$ & $x$ & $x$ & $x$ & $x$ & $x$ & $x$ & $x$ \\
\hline LRRK1 & $x$ & $x$ & $x$ & $x$ & $x$ & & $x$ & $x$ & $x$ & $x$ & $x$ & $x$ & $x$ \\
\hline PCSK6 & $x$ & $x$ & $x$ & $x$ & $x$ & & $x$ & $x$ & $x$ & $x$ & $x$ & $x$ & $\mathrm{X}$ \\
\hline TARSL2 & X & X & & X & X & & X & X & X & X & X & X & $X$ \\
\hline
\end{tabular}

The primary critical region, where all deletions overlap, is highlighted in light gray. The secondary critical region, where all but one deletion overlap, is highlighted in dark gray. The genes within the region and surrounding region are listed in the order that they occur on the chromosome. An $\mathrm{X}$ indicates that the gene is involved in the chromosomal imbalance in that patient. The patient and the database (C: Cooper et al. ${ }^{13} \mathrm{D}$ : DECIPHER, I: ISCA, W: CHDWiki, and M: the University of Michigan) or publication from which they were gathered is listed along the top row. Along the second row is the designation of whether the rearrangement was a deletion or duplication. In the third row is the type of the cardiac defect observed if known (if unknown is listed as "HEART"). Nomenclature for heart defects is the same as for Table 1.

Note that there is one chromosomal imbalance that was in close proximity to but did not involve the genes in the primary critical region. "Ao" indicates dilatation of the aortic root in one patient. 
Table 5. DiGeorge Syndrome Region on Chromosome 22q11.2 with Surrounding Genes

\begin{tabular}{|c|c|c|c|c|c|c|c|c|}
\hline Database & Database ID & $\mathrm{CHD}$ & Chromo & Type & Genome Build & Boundary 1 & Boundary 2 & Locus \\
\hline I & nssv579955 & VSD & 22 & DEL & hg19 & 17019015 & 20718227 & TBX1 \\
\hline I & nssv575290 & HEART & 22 & DEL & hg19 & 18706001 & 20659606 & TBX1 \\
\hline I & nssv575290 & VSD & 22 & DEL & hg19 & 18890271 & 20659606 & TBX1 \\
\hline W & 1412 & VSD & 22 & DEL & hg19 & 18894835 & 20659606 & TBX1 \\
\hline C & 9908014 & HEART & 22 & DEL & hg19 & 18986906 & 20246906 & TBX1 \\
\hline I & nssv577056 & HEART & 22 & DEL & hg19 & 19771355 & 21123068 & TBX1 \\
\hline I & nssv579962 & CoA & 22 & DUP & hg19 & 19074579 & 19928090 & TBX1 \\
\hline I & nssv1603215 & HEART & 22 & DEL & hg19 & 18660553 & 21455556 & TBX1/CRKL \\
\hline I & nssv579970 & VSD & 22 & DEL & hg19 & 18661724 & 21561514 & TBX1/CRKL \\
\hline I & nssv579984 & HEART & 22 & DEL & hg19 & 18661724 & 21561514 & TBX1/CRKL \\
\hline TM & 19 & TOF & 22 & DEL & hg19 & 18805856 & 21721725 & TBX1/CRKL \\
\hline G & 2573 & TOF & 22 & DEL & hg19 & 18810089 & 21153772 & TBX1/CRKL \\
\hline G & 2360 & TOF & 22 & DEL & hg19 & 18895187 & 21463936 & TBX1/CRKL \\
\hline I & nssv579993 & Al & 22 & DEL & hg19 & 18909032 & 21306115 & TBX1/CRKL \\
\hline I & nssv1603983 & HEART & 22 & DEL & hg19 & 18919469 & 21456772 & TBX1/CRKL \\
\hline D & 2213 & HEART & 22 & DEL & hg19 & 18919469 & 21460658 & TBX1/CRKL \\
\hline D & 256300 & VSD & 22 & DEL & hg19 & 18919469 & 21460658 & TBX1/CRKL \\
\hline C & 9882869 & HEART & 22 & DEL & hg19 & 18919469 & 21460658 & TBX1/CRKL \\
\hline C & 9893576 & HEART & 22 & DEL & hg19 & 18919469 & 21460658 & TBX1/CRKL \\
\hline C & 9883354 & TOF & 22 & DEL & hg19 & 18919469 & 21460658 & TBX1/CRKL \\
\hline C & 9883678 & HEART & 22 & DEL & hg19 & 18919742 & 21440655 & TBX1/CRKL \\
\hline C & 9883488 & TOF & 22 & DEL & hg19 & 18919742 & 21440655 & TBX1/CRKL \\
\hline C & 9881580 & HEART & 22 & DEL & hg19 & 18919941 & 21440515 & TBX1/CRKL \\
\hline D & 262934 & HEART & 22 & DEL & hg19 & 18919941 & 21440515 & TBX1/CRKL \\
\hline I & nssv579999 & TOF & 22 & DEL & hg19 & 18919942 & 21440514 & TBX1/CRKL \\
\hline C & 9906174 & HEART & 22 & DEL & hg19 & 18919942 & 21440514 & TBX1/CRKL \\
\hline C & 9892257 & $\mathrm{CoA}$ & 22 & DEL & hg19 & 18919942 & 21440514 & TBX1/CRKL \\
\hline I & nssv582251 & ASD & 22 & DEL & hg19 & 18919942 & 21505417 & TBX1/CRKL \\
\hline I & nssv576304 & VSD & 22 & DEL & hg19 & 18919942 & 21505417 & TBX1/CRKL \\
\hline I & nssv580013 & HEART & 22 & DEL & hg19 & 18919942 & 21505417 & TBX1/CRKL \\
\hline I & nssv580012 & HEART & 22 & DEL & hg19 & 18919942 & 21505417 & TBX1/CRKL \\
\hline I & nssv580007 & $\mathrm{CHF}$ & 22 & DEL & hg19 & 18919942 & 21505417 & TBX1/CRKL \\
\hline I & nssv575367 & ASD & 22 & DEL & hg19 & 18919942 & 21561514 & TBX1/CRKL \\
\hline I & nssv580006 & HEART & 22 & DEL & hg19 & 18938161 & 21455556 & TBX1/CRKL \\
\hline I & nssv583020 & HEART & 22 & DEL & hg19 & 18938161 & 21455556 & TBX1/CRKL \\
\hline I & nssv580004 & PS & 22 & DEL & hg19 & 18938161 & 21455556 & TBX1/CRKL \\
\hline I & nssv582339 & VSD & 22 & DEL & hg19 & 19023824 & 21798755 & TBX1/CRKL \\
\hline I & nssv580045 & SAS & 22 & DUP & hg19 & 18627818 & 21940122 & TBX1/CRKL \\
\hline I & nssv580051 & AVSD & 22 & DUP & hg19 & 18660553 & 21455556 & TBX1/CRKL \\
\hline I & nssv580052 & HEART & 22 & DUP & hg19 & 18781534 & 21465835 & TBX1/CRKL \\
\hline C & 9893158 & HEART & 22 & DUP & hg19 & 18919942 & 21801604 & TBX1/CRKL \\
\hline D & 1640 & AVSD & 22 & DUP & hg19 & 19573160 & 21461017 & TBX1/CRKL \\
\hline D & 251689 & TOF & 22 & DEL & hg19 & 20330744 & 21465481 & CRKL \\
\hline D & 254167 & AAo & 22 & DEL & hg19 & 20659547 & 21561514 & CRKL \\
\hline TM & 9 & HEART & 22 & DEL & hg19 & 20733427 & 21505417 & CRKL \\
\hline $\mathrm{D}$ & 768 & ASD; PDA & 22 & DEL & hg19 & 20734244 & 21460658 & CRKL \\
\hline D & 986 & VSD & 22 & DEL & hg19 & 20743536 & 21462353 & CRKL \\
\hline TM & 25 & VSD & 22 & DEL & hg19 & 20754422 & 21440514 & CRKL \\
\hline D & 262483 & SAS & 22 & DUP & hg19 & 20763207 & 21461765 & CRKL \\
\hline I & nssv580061 & TOF & 22 & DUP & hg19 & 20769981 & 21037727 & CRKL \\
\hline I & nssv580065 & VSD & 22 & DEL & hg19 & 20372210 & 22548710 & CRKL/MAPK1 \\
\hline W & 1488 & CAT & 22 & DEL & hg19 & 20976969 & 22484320 & CRKL/MAPK1 \\
\hline S & BOOBEJC & ASD & 22 & DEL & hg19 & 21075575 & 22467350 & CRKL/MAPK1 \\
\hline I & nssv575749 & HEART & 22 & DUP & hg19 & 21025653 & 22467351 & CRKL/MAPK1 \\
\hline TM & 21 & CAT & 22 & DEL & hg19 & 21692108 & 23575642 & MAPK1 \\
\hline S & B00B1CM & AVSD & 22 & DEL & hg19 & 21721591 & 22970128 & MAPK1 \\
\hline W & 98 & AVSD & 22 & DEL & hg19 & 21721591 & 22970128 & MAPK1 \\
\hline C & 9895786 & VSD & 22 & DEL & hg19 & 21798104 & 23739485 & MAPK1 \\
\hline D & 2366 & HEART & 22 & DEL & hg19 & 21799773 & 23654237 & MAPK1 \\
\hline S & B00BE7D & HEART & 22 & DEL & hg19 & 21808750 & 24643264 & MAPK1 \\
\hline D & 251833 & HEART & 22 & DEL & hg19 & 21811979 & 24616199 & MAPK1 \\
\hline D & 251833 & Al & 22 & DEL & hg19 & 21939922 & 24643109 & MAPK1 \\
\hline D & 250255 & VSD; ASD; PDA & 22 & DEL & hg19 & 22095272 & 22834113 & MAPK1 \\
\hline D & 248709 & CAT & 22 & DEL & hg19 & 22095272 & 22834113 & MAPK1 \\
\hline I & nssv580074 & CAT & 22 & DEL & hg19 & 22095272 & 22834113 & MAPK1 \\
\hline I & nssv580080 & CAT & 22 & DEL & hg19 & 22095272 & 22834113 & MAPK1 \\
\hline TM & 29 & VSD; RAO & 22 & $\mathrm{DEL}$ & hg19 & 22095272 & 22834113 & MAPK1 \\
\hline
\end{tabular}




\begin{tabular}{lllllllll} 
Table 5. & Continued & \multicolumn{7}{l}{} \\
\hline Database & Database ID & CHD & Chromo & Type & Genome Build & Boundary 1 & Boundary 2 & Locus \\
\hline C & 9890170 & BAV & 22 & DEL & hg19 & 22095272 & 22834113 & MAPK1 \\
W & 21 & CAT & 22 & DEL & hg19 & 22095272 & 22834113 & MAPK1 \\
W & 18 & CAT & 22 & DEL & hg19 & 22115848 & 23696229 & MAPK1 \\
W & 24 & CAT & 22 & DEL & hg19 & 22115848 & 23696229 & MAPK1 \\
W & 23 & VSD & 22 & DEL & hg19 & 22115848 & 23696229 & MAPK1 \\
W & 22 & TA & 22 & DUP & hg19 & 21934556 & 22381654 & MAPK1 \\
W & 26 & CAT & 22 & DEL & hg19 & 19031487 & 23071636 & TBX1/CRKL/MAPK1 \\
W & 28 & VSD & 22 & DUP & hg19 & 17397498 & 51178264 & TBX1/CRKL/MAPK1 \\
W & 1003 & VSD & 22 & DUP & hg19 & 17397498 & 51178264 & TBX1/CRKL/MAPK1 \\
W & 27 & DORV; SI & 22 & DUP & hg19 & 18546349 & 22336469 & TBX1/CRKL/MAPK1 \\
S & B00BDZ8 & ECG & 22 & DUP & hg19 & 19174809 & 22264418 & TBX1/CRKL/MAPK1 \\
S & B00B0MB & CAT & 22 & DUP & hg19 & 19771355 & 19771891 & \\
S & B00B15I & TA; TGA & 22 & DUP & hg19 & 22308883 & 22573637 & TOP3B \\
S & B00BQP9 & TOF & 22 & DUP & hg19 & 22311326 & 22573637 & TOP3B \\
W & 29 & AS & 22 & DEL & hg19 & 22312383 & 22573637 & TOP3B \\
W & 25 & TOF & 22 & DEL & hg19 & 22315312 & 22573637 & TOP3B \\
S & B009FPG & BAV & 22 & DUP & hg19 & 22315312 & 22571854 & TOP3B \\
S & B00B0D1 & TOF & 22 & DUP & hg19 & 22315312 & 22573637 & TOP3B
\end{tabular}

Data presented for each case includes the database source, the case ID number, the type of heart defect noted (CHD), the chromosome affected by the deletion or duplication (Chrom), the type of chromosomal imbalance (deletion [DEL] or duplication [DUP]) identification, the genome build of the annotated sequence involved (all hg19), and the approximate proximal (Boundary 1) and distal (Boundary 2) boundaries of the observed imbalance, and the candidate gene or genes involved in the imbalance (Locus). The chromosomal imbalances were divided into those involving just TBX1, TBX1 and CRKL, CRKL only, CRKL and MAPK1, $M A P K 1$ only, and all three. Shading indicates involvement of more that one candidate gene. In six cases, a small chromosomal rearrangement occurred between CRKL and MAPK1 but did not involve either gene. All of those cases did involve imbalance of the gene TOP3B, a gene not known to be involved in heart development. Only one chromosomal imbalance of $22 q 11 \mathrm{did}$ not involve one of those four loci. Nomenclature for heart defects is the same as for Table 1 . Sources listed include the following databases and publications: Cooper et al. ${ }^{13}$ (C), DECIPHER (D), ISCA (I), CHDWiki (W), Tomita-Mitchell et al. ${ }^{12}$ (TM), Greenway et al..$^{11}$ $(\mathrm{G})$, Soemedi et al. ${ }^{14}(\mathrm{~S})$, and the University of Michigan (M).

searchable, and well-annotated database of wellphenotyped patients with clearly defined chromosomal imbalances. The obstacles to achieving this goal are not insurmountable and would yield enormous benefits for all patients with developmental defects, including heart defects.

Although there are very important limitations to the databases in their current state that restrict the ability to make conclusions based on these data, the database review suggested several important considerations with regard to human heart development and the pathogenesis of human congenital cardiac defects. Most importantly, the database review reinforces the observation that haploinsufficiency or duplication of even genes known to be critical for heart development only results in heart defects in a subset of cases. For instance, haploinsufficiency of TBX1 led to clinically significant heart defects in $27 \%$ of patients in the Signature dataset and $40 \%$ in the DECIPHER database. The Signature dataset may have a lower ascertainment and reporting bias but also may under-report or under-detect heart defects. The DECIPHER database is more prone to ascertainment and reporting bias, which may inflate the estimated frequency of heart defects in patients with $22 \mathrm{q} 11$ deletions. Clearly, other factors are involved that help determine whether an individual with a genetic predisposition, such as TBX1 haploinsufficiency, manifests a significant cardiac abnormality.
At least some of the clinical variability in cases of chromosome $22 \mathrm{q} 11$ deletion may be related to the extent of the deletion. In the database, as has been noted in previous studies, most commonly, cases (30 out of 85 reported) with a CHD and a chromosomal imbalance affecting chromosome $22 \mathrm{q} 11$ had an approximately $3 \mathrm{Mb}$ deletion, which included both the TBX1 and CRKL genes. A smaller $1.5 \mathrm{Mb}$ deletion involving TBX1 but not $C R K L$ was noted in six patients in the database. The smaller deletion has been previously noted to account for DiGeorge syndrome in approximately $7 \%$ of cases and the larger deletion in $88 \% .{ }^{29,30}$ The smaller deletion has been noted to be sufficient to produce the full DiGeorge syndrome phenotype ${ }^{31}$ including conotruncal heart defects, ${ }^{32}$ but there has been noted to be an important difference in the rate at which the $1.5 \mathrm{Mb}$ deletion and the $3 \mathrm{Mb}$ deletion are passed to offspring. ${ }^{33}$ The reduced rate of transmission of the larger deletion may indicate that the early developmental defects are more penetrant or more severe in the patients with the larger deletion. In our database, the patients with the smaller $1.5 \mathrm{Mb}$ deletion had ventricular septal defects and unspecified heart abnormalities while those with the larger $3 \mathrm{Mb}$ deletion, encompassing both TBX1 and CRKL, demonstrated a range of heart defects including TOF (six cases), VSD (three cases), and pulmonary stenosis (one case). Conotruncal heart defects including truncus arteriosus (CAT) and TOF were 
noted in cases involving deletions distal to the $1.5 \mathrm{Mb}$ smaller DiGeorge syndrome deletion, including deletions involving (1) the distal part of the $3 \mathrm{Mb}$ deletion region (and including CRKL) and/or (2) deletion of more distal 22q11 including $M A P K 1$. The ability of $22 \mathrm{q} 11$ deletions that do not involve $T B X 1$ to result in conotruncal cardiac defects has been previously noted in cases involving the loss of both CRKL and MAPK1. ${ }^{28}$ Therefore, the concurrent loss of 2 or more genes involved in cardiac development as occurs with the simultaneous loss of TBX1 and CRKL in the larger and more common $3 \mathrm{Mb}$ DiGeorge syndrome deletion or with the less common simultaneous loss of CRKL and MAPK1 may enhance the penetrance of cardiac defects in patients with $22 \mathrm{q} 11$ deletions. This is supported by knockout studies in mice that demonstrated a higher penetrance and severity of cardiac defects in mice haplosufficient for both TBX1 and CRKL compared to mice haplosufficient for either individually. ${ }^{34}$

CHD penetrance may also vary by disease locus. Chromosomal imbalances involving GATA4 and NKX2-5 are rare but, when they occur, seem to be associated with a high frequency of clinically significant cardiac defects. Few other loci appear to have comparable penetrance with regard to haploinsufficiency and the incidence of heart defects. However, disease genes that reside in regions that are relatively stable (i.e., very rarely involved in chromosomal imbalances) or in regions where chromosomal imbalances are associated with markedly reduced viability may be difficult to detect using this approach.

The generated composite database of each individual case (Supporting Information Table S1) will provide a useful starting point for the identification of novel genomic regions potentially involved in human heart development and the pathogenesis of congenital cardiac defects. Identification of such regions will facilitate the interpretation of genome-wide sequencing data, in the search for the genetic determinants of congenital cardiac defects. As cases are added to the database there may be further refinement of the region determined to be critical for heart development. Examples of how deletion/duplication mapping may be used to restrict candidate regions and identify potential candidate genes are described below.

\section{Locus at Iq24.2}

Deletions of 1q24 are relatively uncommon. There was a report of seven patients with deletion of $1 \mathrm{q} 24.3-1 \mathrm{q} 25$ that overlaps minimally with the CHD CR defined in this study. ${ }^{35}$ Cardiac defects were not noted to be an important feature of their observed phenotype. As noted above, none of the genes within the primary and secondary CRs has a known role in heart development or the pathogenesis of congenital cardiac defects. Of the genes in the primary CR, GORAB, and PRRX1 are expressed in the heart, but loss of function in human patients or in animal models is not associated with heart defects. ${ }^{36-38}$ Similarly, in the secondary CR, VAMP4, and DNM3 are expressed the heart, but no role in cardiac development has been identified. In addition, there are a number of miRNAs that have been identified within the CRs at this locus. Most interesting is mir-214, which is encoded within the DNM3 locus, is highly expressed in the heart and promotes myogenic differentiation. ${ }^{39}$

\section{Locus at $2 q 3 I . I$}

Duplication of chromosome $2 \mathrm{q} 31.1$ has been noted in a 3 generation family with mesomelic dysplasia, ${ }^{40}$ but deletions involving $2 \mathrm{q} 31.1$ are relatively uncommon. ${ }^{41}$ The predominant cardiac lesions in patients with $2 \mathrm{q} 31.1$ deletions that have been recorded in the databases are defects in cardiac septation resulting in ASDs and VSDs. Within the primary $\mathrm{CR}$ on chromosome $2 \mathrm{q} 31$ is $\mathrm{CBF} 1-$ interacting co-repressor (CIR1) (Table 4B). CBF1 (or RBPJ) is a transcriptional repressor whose activity is de-repressed by binding to the Notch intracellular domain, making it a key target in Notch-mediated transcriptional activation. CIR1's high level of expression in the heart and interaction with a signaling pathway critical for heart development make CIR 1 a likely candidate for the observed cardiac defects in these patients..$^{20}$ Other genes within the primary and secondary CRs that are expressed in the heart include PDK1 (pyruvate dehydrogenase kinase), transcription factor $S P 3$, and $Z A K$. $Z A K$ encodes a kinase that activates MAPK $1,{ }^{42}$ another kinase implicated in the pathogenesis of congenital cardiac defects, ${ }^{28}$ and SP3 encodes for a transcription factor that is required for normal heart development in the mouse. ${ }^{21}$

\section{Locus at $15 q 26.3$}

A recurring deletion of chromosome $15 \mathrm{q} 26.3$ described by Rump et al. ${ }^{43}$ was noted to be responsible for a distinct clinical phenotype that had been named Drayer syndrome. Common features include micrognathia, developmental delay, skeletal anomalies and growth failure. As noted above, 
$M E F 2 A$, a transcription factor strongly expressed in smooth muscle throughout the body, including the smooth muscle of the developing heart tube, is a strong candidate for the heart defects associated with $15 \mathrm{q} 26$ deletions as has been previously proposed. ${ }^{44}$ Another candidate within the region is ADAMTS17, which is expressed in the developing heart. ${ }^{45}$ However, deleterious mutations of ADAMTS17 in human patients cause ocular and ophthalmologic abnormalities but have not led to the development of CHDs. ${ }^{45}$

It is important to note that haploinsufficiency of this region did lead to heart defects with related etiologies, as two of the more commonly noted lesions with these deletions, HLHS and CoA, can occur together in families and are often defined as closely related left-sided obstructive lesions. ${ }^{46}$ Therefore, a gene or genes within this region may be an important candidate(s) to consider when evaluating patients with left-sided obstructive lesions including HLHS.

\section{DiGeorge Region}

In several regions, nonoverlapping chromosomal imbalances are associated with cardiac defects, suggesting that more than one gene in the region participates in heart development. Given that (1) the "penetrance" of the cardiac phenotype in response to a chromosomal imbalance is variable and can be quite low even for imbalances involving a gene known to participate in heart development and (2) the incidence of heart defects in the general population is high enough that not all defects can be assumed to be "caused" by the observed imbalance, it can be very difficult to determine the precise extent of the candidate regions and the number of heart development genes involved. One region that may contain more than a single gene involved in heart development is chromosome 22q11, which includes the DiGeorge syndrome CR. As noted above, TBX1, which encodes for a T-box cardiac transcription factor, is within the CR and has been demonstrated in animal models to have an important role in heart development. ${ }^{23,26,47}$ However, nonoverlapping chromosomal imbalances associated with heart defects have suggested the possibility of two additional 22q11 genes involved in heart development, and several lines of evidence support the potential involvement of the CRKL and MAPK1 genes. ${ }^{28,48,49}$ Review of the cases in the databases support the existence of at least three genes on chromosome $22 \mathrm{q} 11$ that contribute to cardiac development.

\section{Limitations}

As noted above, there are a number of important limitations to this study. The databases and publications included in this analysis do not share a common genotyping platform, do not have a consistent approach to phenotyping or phenotype reporting and are entirely voluntary. We have included a supplemental table that contains some basic information regarding each of the reported cases (Supporting Information Table S1). We recognize that our list of 79 loci involved in five or more rearrangements is incomplete and that there will be many instances where (1) multiple candidate genes have been encompassed by a single locus; (2) only a single candidate gene is present where there are several closely spaced candidate regions; (3) "false" loci have been created by database errors, random chance and genomic instability; and (4) "true" loci have been missed due to genomic stability (leading to very few cases of chromosomal imbalance for evaluation) and/or reduced viability of affected embryos. The list is meant to be a preliminary effort to consolidate what is known to date and it will need to be refined or replaced as case reporting becomes more standardized. The supplementary table will serve as a platform for identifying new candidate loci as additional cases are added to the database and will help to further refine existing loci.

\section{Summary}

Despite the limitations of this study, the database analysis demonstrates the potential value of this approach to restrict regions of interest for genes involved in developmental disorders including congenital cardiac defects. The low penetrance for observable cardiac defects associated with most chromosomal imbalances, the infrequent occurrence of chromosomal abnormalities in most genomic regions, and the relatively common occurrence of some types of cardiac defects (such as ASDs and VSDs) in the general population will make it difficult to define CRs based on a single patient or small cohorts. Therefore, there will be tremendous value in establishing standardized processes for reporting observed chromosomal imbalances and associated clinical phenotypes. The refined map of loci involved in human cardiac development will be essential as genome-wide sequencing approaches become more prevalent in the search for the genetic determinants of congenital cardiac defects. 


\section{Acknowledgements}

This study makes use of data generated by (1) the DECIPHER Consortium (a full list of centers who contributed to the generation of the data is available from http:// decipher.sanger.ac.uk and via email from decipher@ sanger.ac.uk; funding for the project was provided by the Wellcome Trust), (2) the ISCA Consortium database (the consortium generates this information using NCBI's database of genomic structual variation [dbVar, http:// www.ncbi.nlm.nih.gov/dbvar/], study nstd37; samples and associated phenotype data were provided by ISCA Consortium member laboratories [http://www.iscaconsortium .org]) and (3) CHDWiki (http://homes.esat.kuleuven.be/ bioiuser/chdwiki/index.php/CHD:Reports). Funding for the study was provided by the Braylon's Gift of Hope Fund (MWR) and the Aaron Stern Professorship (MWR).

Author Contributions: All authors contributed to database and publication review and dataset creation. In addition, MWR, JWI and TT contributed to study design and manuscript preparation.

Corresponding Author: Mark W. Russell, MD, Department of Pediatrics and Communicable Diseases, Division of Pediatric Cardiology, University of Michigan, 1540 E Hospital Drive, Ann Arbor, MI 48109, USA. Tel: (+734) 936-7418; Fax: (+734) 936-9470; E-mail: mruss@med.umich.edu

Accepted in final form: February 22, 2014.

Conflict of interest: None.

\section{References}

1 Ohye RG, Sleeper LA, Mahony L, et al. Comparison of shunt types in the Norwood procedure for single-ventricle lesions. N Engl 7 Med. 2010;362: 1980-1992.

2 Petit CJ. Staged single-ventricle palliation in 2011: outcomes and expectations. Congenit Heart Dis. 2011;6:406-416.

3 Pierpont ME, Basson CT, Benson DW Jr, et al. Genetic basis for congenital heart defects: current knowledge: a scientific statement from the American Heart Association Congenital Cardiac Defects Committee, Council on Cardiovascular Disease in the Young: endorsed by the American Academy of Pediatrics. Circulation. 2007;115:3015-3038.

4 McCulley DJ, Black BL. Transcription factor pathways and congenital heart disease. Curr Top Dev Biol. 2012;100:253-277.

5 Wolf M, Basson CT. The molecular genetics of congenital heart disease: a review of recent developments. Curr Opin Cardiol. 2010;25:192-197.

6 Millan MJ. An epigenetic framework for neurodevelopmental disorders: from pathogenesis to potential therapy. Neuropharmacology. 2013;68:2-82.
7 Zaidi S, Choi M, Wakimoto H, et al. De novo mutations in histone-modifying genes in congenital heart disease. Nature. 2013;498:220-223.

8 Ferencz C, Neill CA, Boughman JA, Rubin JD, Brenner JI, Perry LW. Congenital cardiovascular malformations associated with chromosome abnormalities: an epidemiologic study. 7 Pediatr. 1989; 114:79-86.

9 Firth HV, Richards SM, Bevan AP, et al. DECIPHER: database of chromosomal imbalance and phenotype in humans using ensemble resources. $\mathrm{Am}$ 7 Hum Genet. 2009;84:524-533.

10 Barriot R, Breckpot J, Thienpont B, et al. Collaboratively charting the gene-to-phenotype network of human congenital heart defects. Genome Med. 2010;2:16.

11 Greenway SC, Pereira AC, Lin JC, et al. De novo copy number variants identify new genes and loci in isolated sporadic tetralogy of Fallot. Nat Genet. 2009;41:931-935.

12 Tomita-Mitchell A, Mahnke DK, Struble CA, et al. Human gene copy number spectra analysis in congenital heart malformations. Physiol Genomics. 2012;44:518-541.

13 Cooper GM, Coe BP, Girirajan S, et al. A copy number variation morbidity map of developmental delay. Nat Genet. 2011;43:838-846.

14 Soemedi R, Wilson IJ, Bentham J, et al. Contribution of global rare copy-number variants to the risk of sporadic congenital heart disease. Am $7 \mathrm{Hum}$ Genet. 2012;91:489-501.

15 Baldwin EL, Lee JY, Blake DM, et al. Enhanced detection of clinically relevant genomic imbalances using a targeted plus whole genome oligonucleotide microarray. Genet Med. 2008;10:415-429.

16 Quinonez SC, Hedera P, Barr M, et al. Maternal intrachromosomal insertional translocation leads to recurrent 1q21.3q23.3 deletion in two siblings. Am 7 Med Genet A. 2012;158A:2591-2601.

17 Thienpont B, Zhang L, Postma AV, et al. Haploinsufficiency of TAB2 causes congenital heart defects in humans. Am 7 Hum Genet. 2010;86:839-849.

18 Bassett AS, Chow EW, Husted J, et al. Clinical features of 78 adults with 22q11 Deletion Syndrome. Am 7 Med Genet A. 2005;138:307-313.

19 Garg V, Muth AN, Ransom JF, et al. Mutations in NOTCH1 cause aortic valve disease. Nature. 2005;437:270-274.

20 Hsieh JJ, Zhou S, Chen L, Young DB, Hayward SD. CIR, a corepressor linking the DNA binding factor CBF1 to the histone deacetylase complex. Proc Natl Acad Sci US A. 1999;96:23-28.

21 van Loo PF, Mahtab EA, Wisse LJ, et al. Transcription factor $\mathrm{Sp} 3$ knockout mice display serious cardiac malformations. Mol Cell Biol. 2007;27:85718582.

22 Subramanian SV, Nadal-Ginard B. Early expression of the different isoforms of the myocyte enhancer 
factor-2 (MEF2) protein in myogenic as well as nonmyogenic cell lineages during mouse embryogenesis. Mech Dev. 1996;57:103-112.

23 Yagi H, Furutani Y, Hamada H, et al. Role of TBX1 in human del22q11.2 syndrome. Lancet. 2003;362: 1366-1373.

24 Lindsay EA, Vitelli F, Su H, et al. Tbx1 haploinsufficieny in the DiGeorge syndrome region causes aortic arch defects in mice. Nature. 2001;410:97101.

25 Merscher S, Funke B, Epstein JA, et al. TBX1 is responsible for cardiovascular defects in velocardio-facial/DiGeorge syndrome. Cell. 2001;104: 619-629.

26 Jerome LA, Papaioannou VE. DiGeorge syndrome phenotype in mice mutant for the T-box gene, Tbx1. Nat Genet. 2001;27:286-291.

27 Momma K. Cardiovascular anomalies associated with chromosome 22q11.2 deletion syndrome. Am 7 Cardiol. 2010;105:1617-1624.

28 Breckpot J, Thienpont B, Bauters M, et al. Congenital heart defects in a novel recurrent $22 \mathrm{q} 11.2$ deletion harboring the genes CRKL and MAPK1. Am 7 Med Genet A. 2012;158A:574-580.

29 Shaikh TH, Kurahashi H, Saitta SC, et al. Chromosome 22-specific low copy repeats and the 22q11.2 deletion syndrome: genomic organization and deletion endpoint analysis. Hum Mol Genet. 2000;9:489501.

30 Saitta SC, Harris SE, Gaeth AP, et al. Aberrant interchromosomal exchanges are the predominant cause of the 22q11.2 deletion. Hum Mol Genet. 2004; 13:417-428.

31 Morrow B, Goldberg R, Carlson C, et al. Molecular definition of the $22 \mathrm{q} 11$ deletions in velo-cardiofacial syndrome. Am 7 Hum Genet. 1995;56:13911403.

32 Rauch A, Zink S, Zweier C, et al. Systematic assessment of atypical deletions reveals genotypephenotype correlation in $22 \mathrm{q} 11.2$. 7 Med Genet. 2005;42:871-876.

33 Adeyinka A, Stockero KJ, Flynn HC, Lorentz CP, Ketterling RP, Jalal SM. Familial 22q11.2 deletions in DiGeorge/velocardiofacial syndrome are predominantly smaller than the commonly observed 3Mb. Genet Med. 2004;6:517-520.

34 Guris DL, Duester G, Papaioannou VE, Imamoto A. Dose-dependent interaction of Tbx1 and Crkl and locally aberrant RA signaling in a model of del22q11 syndrome. Dev Cell. 2006;10:81-92.

35 Burkardt DD, Rosenfeld JA, Helgeson ML, et al. Distinctive phenotype in 9 patients with deletion of chromosome 1q24-q25. Am 7 Med Genet A. 2011; 155A:1336-1351.

36 Hennies HC, Kornak U, Zhang H, et al. Gerodermia osteodysplastica is caused by mutations in SCYL1BP1, a Rab-6 interacting golgin. Nat Genet. 2008;40:1410-1412.
37 Sergi C, Kamnasaran D. PRRX1 is mutated in a fetus with agnathia-otocephaly. Clin Genet. 2011; 79:293-295.

38 Martin JF, Bradley A, Olson EN. The paired-like homeo box gene MHox is required for early events of skeletogenesis in multiple lineages. Genes Dev. 1995;9:1237-1249.

39 Liu J, Luo XJ, Xiong AW, et al. MicroRNA-214 promotes myogenic differentiation by facilitating exit from mitosis via down-regulation of protooncogene N-ras. 7 Biol Chem. 2010;285:26599_ 26607.

40 Cho TJ, Kim OH, Choi IH, et al. A dominant mesomelic dysplasia associated with a $1.0-\mathrm{Mb}$ microduplication of HOXD gene cluster at $2 \mathrm{q} 31.1$. 7 Med Genet. 2010;47:638-639.

41 Theisen A, Rosenfeld JA, Shane K, et al. Refinement of the region for split hand/foot malformation 5 on 2q31.1. Mol Syndromol. 2010;1:262271.

42 Gotoh I, Adachi M, Nishida E. Identification and characterization of a novel MAP kinase kinase kinase, MLTK. 7 Biol Chem. 2001;276:42764286.

43 Rump P, Dijkhuizen T, Sikkema-Raddatz B, et al. Drayer's syndrome of mental retardation, microcephaly, short stature and absent phalanges is caused by a recurrent deletion of chromosome 15 (q26.2 $\rightarrow$ qter). Clin Genet. 2008;74:455-462.

44 Tonnies H, Schulze I, Hennies H, Neumann LM, Keitzer R, Neitzel H. De novo terminal deletion of chromosome 15q26.1 characterised by comparative genomic hybridisation and FISH with locus specific probes. 7 Med Genet. 2001;38:617-621.

45 Morales J, Al-Sharif L, Khalil DS, et al. Homozygous mutations in ADAMTS10 and ADAMTS17 cause lenticular myopia, ectopia lentis, glaucoma, spherophakia, and short stature. Am 7 Hum Genet. 2009;85:558-568.

46 Hinton RB, Martin LJ, Rame-Gowda S, Tabangin ME, Cripe LH, Benson DW. Hypoplastic left heart syndrome links to chromosomes $10 \mathrm{q}$ and $6 \mathrm{q}$ and is genetically related to bicuspid aortic valve. $7 \mathrm{Am}$ Coll Cardiol. 2009;53:1065-1071.

47 Vitelli F, Morishima M, Taddei I, Lindsay EA, Baldini A. Tbx1 mutation causes multiple cardiovascular defects and disrupts neural crest and cranial nerve migratory pathways. Hum Mol Genet. 2002;11:915-922.

48 Fagerberg CR, Graakjaer J, Heinl UD, et al. Heart defects and other features of the $22 \mathrm{q} 11$ distal deletion syndrome. Eur 7 Med Genet. 2013;56:98107.

49 Guris DL, Fantes J, Tara D, Druker BJ, Imamoto A. Mice lacking the homologue of the human $22 \mathrm{q} 11.2$ gene CRKL phenocopy neurocristopathies of DiGeorge syndrome. Nat Genet. 2001;27:293298. 


\section{Supporting Information}

Additional Supporting Information may be found in the online version of this article at the publisher's web-site:

Table S1. All 1762 cases collected for this study are presented. Data presented for each case includes the database source, the case ID number, the type of heart defect noted (CHD), the chromosome affected by the deletion or duplication (Chrom), the type of chromosomal imbalance (deletion [DEL] or duplication [DUP]) identification, the genome build of the annotated sequence involved (all hg19), and the approximate proximal (Boundary 1) and distal (Boundary 2) boundaries of the observed imbalance, and the candidate gene or genes involved in the imbalance (Locus). Loci highlighted in red were affected in 5 or more patients with heart defects. For each case, the chromosome (Chrom) and approximate genetic location (Genome Reference Consortium Human Build 37 [GRCh37/hg19]), a gene within the minimal region of overlap, the observed heart defects and the source of the case (database or publication) are shown. The gene listed is not the only one within the critical region but is a representative one and, if one is present, will be the gene within the interval determined to have a role in heart development. Identification of all genes in the primary and secondary critical regions would require further mapping as noted in Tables 4 and 5 . Heart defects listed include coarctation of the aorta (CoA), interrupted aortic arch (IAA), hypoplastic left heart syndrome (HLHS), atrial and ventricular septal defects (ASDs and VSDs), atrioventricular septal defect (AVSD), tetralogy of Fallot (TOF), double outlet right ventricle (DORV), bicuspid aortic valve (BAV), truncus arteriosus (CAT), situs inversus (SI), heterotaxy (HET), supravalvar aortic and pulmonary stenosis (SVAS and SVPS), aortic stenosis or insufficiency (AS or AI), pulmonary stenosis or insufficiency (PS or PI), tricuspid stenosis or regurgitation (TS or TR), mitral stenosis or regurgitation (MS or MR), total or partial anomalous venous return (TAPVR or PAPVR), tricuspid atresia (TA), pulmonary atresia (PA), patent ductus arteriosus (PDA), left or bilateral superior vena cava (LSVC or BSVC), cardiomyopathy and left ventricular noncompaction (CM and LVNC), and Ebstein's anomaly (EBS). If the heart defect wasn't described then "HEART" is listed. Sources listed include the following databases and publications: Cooper et al. ${ }^{13}$ (C), DECIPHER (D), ISCA (I), CHDWiki (W), Tomita-Mitchell et al. ${ }^{12}$ (TM), Greenway et al. ${ }^{11}$ (G), Soemedi et al. ${ }^{14}(\mathrm{~S})$, and the University of Michigan (M). 